\title{
Herramientas Biotecnológicas en Fitopatología
}

\author{
V. Pallás, C. Escobar, P. Rodríguez-Palenzuela y J.F. Marcos \\ Editores
}

\begin{abstract}
Esta obra es fruto del esfuerzo de más de sesenta especialistas en los diferentes campos de la Fitopatología y del empeño de la Sociedad Española de Fitopatología por cubrir un aspecto sin duda deficitario en libros de lengua castellana. Pretende constituirse en una herramienta de utilidad para profesores, estudiantes, técnicos e investigadores que trabajan o están interesados en el campo de la Fitopatología.
\end{abstract}

En el libro se presentan los últimos avances metodológicos derivados de la Biotecnología, en su aplicación al campo de la Fitopatología. La primera parte del libro describe fundamentalmente aproximaciones experimentales para la caracterización de patógenos y de su interacción con la planta. Se describen de manera pormenorizada nuevas metodologías de identificación de expresión génica diferencial, y también genómicas como son la transcriptómica y la proteómica. Se destaca especialmente la importancia que el conocimiento y utilización de la bioinformática tiene en este contexto. Asimismo se han incluido los últimos adelantos en la caracterización de la variabilidad de fitopatógenos mediante metodologías moleculares y en su transformación genética como herramienta angular de estudio. Como un producto de esto último, a continuación se detallan las principales técnicas derivadas de la utilización de las proteínas fluorescentes en fitopatología, un campo que ha revolucionado los estudios bioquímicos y celulares. Finalmente, el último tercio del libro consiste en capítulos que ponen de manifiesto la utilización de nuevas estrategias en el control biotecnológico de los principales patógenos de plantas.

\section{Herramientas Biotecnológicas en Fitopatología \\ V. Pallás, C. Escobar \\ P. Rodríguez-Palenzuela y J.F. Marcos (eds.)}

Coedición

Sociedad Española de Fitopatología /

Ediciones Mundi-Prensa

Editor: Mundi Prensa Libros S. A.

España

ISBN: 84-8476-319-6

464 pp., gráficos e ilustraciones.

Fecha de publicación: 2008.

Precio: $49 €$

http://www.mundiprensa.com

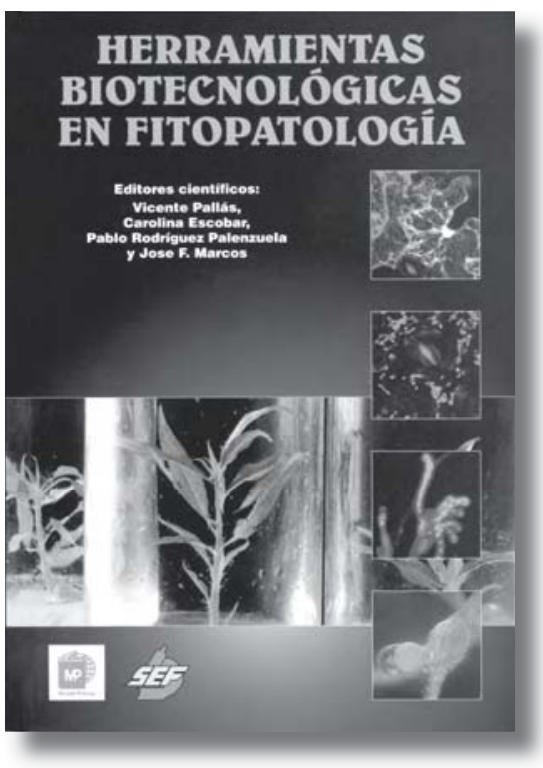

